\title{
Triple-entry accounting, blockchain and next of kin: Towards a standardization of ledger terminology
}

\author{
Juan Ignacio Ibañez ${ }^{1}$ \\ Chris N. Bayer ${ }^{2}$ \\ Paolo Tasca ${ }^{3}$ \\ Jiahua $\mathrm{Xu}^{4}$
}

Working paper

Current version: 20 January, 2021

\begin{abstract}
Triple-entry accounting (TEA) is a novel application in the blockchain universe. Its Wild Wild West status is accompanied by a lack of consistent and comprehensive set of categories, a state of play that impedes a proper apprehension of the technology, leading to contradictions and to overlooking specificity. In order to clearly delineate the confines of TEA, we create a typology to distinguish between essential elements such as accounting and bookkeeping, as well as between decentralized systems, distributed ledgers and distributed journals.

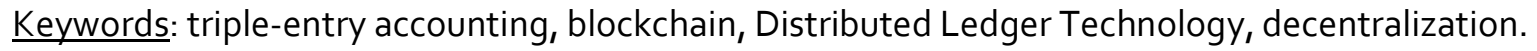

\section{INTRODUCTION}

Triple-entry accounting (TEA) is one of the most innovative concepts of the past decades. It introduces a shared transaction record that constitutes a single source of truth, which is secured through triple-signed receipts and is usually maintained by means of blockchain. This idea was first introduced through lan Grigg's Ricardo Payment System beginning in 1995. In 1998, Todd Boyle independently started to develop Shared Transaction Repositories (STRs), with some influence

${ }^{1}$ Centre for Blockchain Technologies, University College of London.

${ }^{2}$ Centre for Blockchain Technologies, University College of London.

${ }^{3}$ Centre for Blockchain Technologies, University College of London.

${ }^{4}$ Centre for Blockchain Technologies, University College of London. 
from William E. McCarthy's REA accounting model. In 2004, Grigg and Boyle converged, and the latter's work was integrated onto the former's. (Ibañez et al, 2020)

While TEA is extremely innovative, there is a dearth in academic research on the topic [TEA] is extremely limited" (Cai, 2019: 3). This includes attempts to specify the meaning of the terms at use. Meanwhile, practitioners appear not to be putting much effort into a comprehensive conceptualization of TEA and related terms. In turn, they focus on the technical aspects of their product, while taking the vocabulary for granted. This is illustrated by the fact that most companies developing or commercializing TEA projects rarely specify the terms used in their whitepapers.

For instance, The Accounting Blockchain's whitepaper simply defines TEA as the act of recording a transaction in the sets of books of the two parties to the transactions simultaneously and does no further attempt at conceptualization $(A B, 2018)$. Provenance Blockchain does not mention the concept of TEA in its whitepaper (Figure Technologies). The same is the case of another TEA use case: Auditchain (2018). ${ }^{5}$

Similarly, Open Transactions' whitepaper only states that "we proposed the use of triple-signed receipts" (Odom, 2015: 6), without further explanation. Request's whitepaper only claims that "it represents a switch from double-entry accounting to triple-entry accounting" (Request, 2018: 12), also without further explanation. This is also the case for Ledgerium's whitepaper, which only mentions that "we utilize a decentralized ledger through a triple entry accounting system" (Mehmood et al., 2019).

In a similar fashion, Corda's only explanation of the term is that the design was "inspired by previous work, including that (...) on triple entry accounting" (Brown: 17). PayPie (2018: 5) also only explains that "Adding blockchain record in the world of debit and credit effectively creates a triple entry accounting system." Only Pacio's (2020) whitepaper contains some conceptual effort, with a detailed Standardized Semantic Information Model describing how its TEA system would work, as well as prerequisites for a functional TEA system.

The concept of TEA is thus rarely defined. It appears, however, that it is often assumed to mean a shared ledger - and advertised as a decentralized shared ledger if blockchain technology is used.

\footnotetext{
5 However, Provenance has been advertised as a TEA use paper by board member Anthony Pompliano (2019), as has Auditchain (2019) in its website. We were able to confirm this in interviews with both Anthony Pompliano and Jason Meyers (founder of Auditchain).
} 
Nonetheless, were TEA equivalent to a shared ledger, there would be no need for the concept of TEA in the first place, which suggests that a TEA system is a sub-type of shared ledger.

Matters are complicated further by the question of whether Bitcoin is a TEA system. It is often described as one (Grigg 2011; see also Tyra 2014) but, were this to be the case, it would pose the question of whether all other cryptocurrencies are also TEA use cases. If so, then one is left to wonder where the specificity of products specifically advertised as TEA would lie.

Moreover, Bitcoin is the use case that introduced blockchain technology and it is speculated that TEA was one of the influences behind blockchain (Ibañez et al, 2020). This raises the question of whether there is anything intrinsically TEA-like in blockchain technology and if so (given that blockchains would constitute TEA by definition), we should inquire what sense it makes to speak about blockchain-based TEA systems, other than a redundancy.

This leads to the enquiry of what blockchain is, as well as what (if any) difference lies with the concept of distributed ledger technology or DLT. Nevertheless, these notions are also elusive: the prime characteristic of DLTs is not that they are distributed, as distributed systems need not be DLTs. For many what distinguishes distributed ledger technology does not seem to be the fact that it is distributed, but that it is decentralized (source). However, a number of DLTs are not fully decentralized. Bitcoin, for instance, displays centralization in its mining pools. Yet it be hard to argue that this makes Bitcoin any less of a DLT.

A number of papers have attempted to build a taxonomy for blockchain/DLT systems (Ballanedies et al, 2018; Beinke et al, 2018; Garay and Kiayias, 2020; Glaser and Bezzenberger, 2015; Ismail et al, 2019; Labazova et al, 2019; Mohsin et al, 2019; Sarkintudu et al, 2018; Tasca and Tessone, 2019; Walsh et al, 2016; Xu et al, 2020). Nevertheless, they tend to focus in organizing a typology of possible systems, usually taking the higher-level categories for granted.

For the reasons explained above, there is a deficit in this field of research. Existing categories are insufficient to give a proper account of TEA. This includes extant blockchain taxonomies.

This paper sets out to fill in this gap. We build on existing research that describes the taxonomy and landscape of accounting and DLT. We find that an adequate typology to give account of TEA requires the introduction of accounting vocabulary, not just for TEA, but also for DLT in general. 
With this goal in mind, this paper is structured in the following manner. First, we lay out the methods employed. Second, we present a background discussion of the distinction between distributed systems and decentralized systems, as well as the one between accounting and bookkeeping, and journals and ledgers. Third, we define TEA and specify the architecture of a TEA system. Fourth, based on the previous steps, we construct a typology to clarify terminological misunderstandings and set the stage for further analysis. Fifth, we conclude the paper with summary observations and recommendations for further research.

\section{Methodology}

Approaching the topic from the perspective of accounting theory and practice, this study elaborates a typology of the categories relevant to TEA and of the architectural requirements and possibilities of a TEA system. This is done, firstly, through a literature review. The literature consulted, quoted throughout the paper, notably covers the disciplines of accounting and computing in general, and of TEA, cryptography, DLT and blockchain in particular. Secondly, we conduct key informant interviews per phone or per email correspondence with salient individuals in the world of TEA. The interviewees are listed in Appendix B.

\section{ResUlts}

Our research yielded the following finding: the coherent usage of accounting vocabulary is necessary for a proper apprehension of TEA, DLT systems and blockchain. It has been often stated that "blockchain is fundamentally an accounting technology" (ICAEW, 2018: 1), yet not only have the main usages of the blockchain so far -e.g. cryptocurrencies- not been about accounting, but also accounting terminology has been used with excessive latitude until the present.

In this direction, we find that the specificity of DLT-based TEA systems can only be apprehended by applying the distinction, used in the accounting discipline, between bookkeeping and accounting. Furthermore, we find that the distinction between journals and ledgers as the two possible types of books is also important to sustain this specificity. Moreover, we find that a correct 
conceptualization of the term distributed ledger technology requires preliminary awareness of series of contrasts.

This section contains a detailed presentation of our findings.

\subsection{Preliminary Concepts: Decentralization, Distribution, Accounting AND DLT}

In this section, we point out the distinction between distributed and decentralized systems, together

with the divide between (triple-entry) accounting and (triple-entry) bookkeeping, and between Distributed Book Technology (DBT), Distributed Journal Technology (DJT) and Distributed Ledger Technology (DLT).

\subsubsection{The Distinction Between the Centralized, the Decentralized and the Distributed}

In 1964, Paul Baran (1964: 1) claimed that there were two types of networks: "centralized (or star) and distributed (or grid or mesh)". He also stated that "in practice, a mixture of star and mesh is used to form communication networks (...) a "decentralized" network." Baran's typology is shown in Figure 1. 


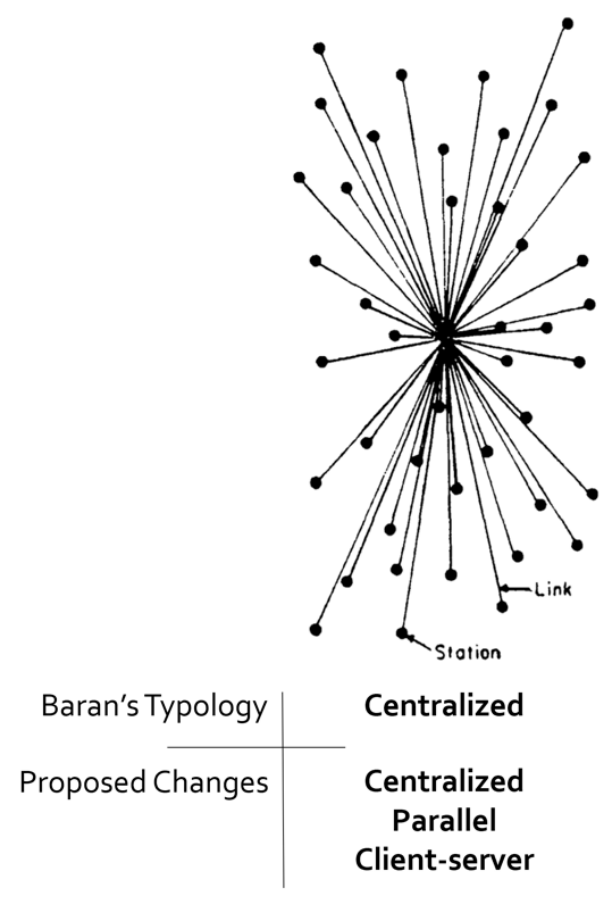

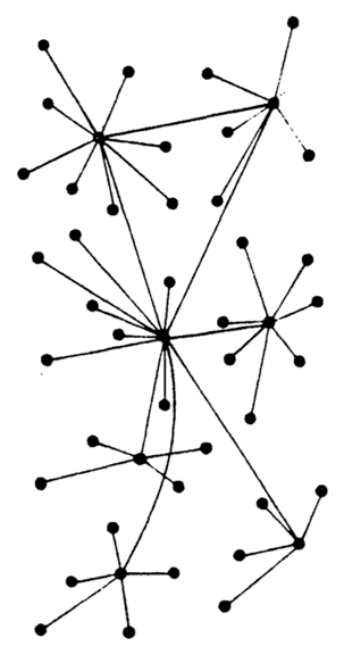

Decentralized

(Less) Centralized Distributed Client-server or $\mathrm{P}_{2} \mathrm{P}$

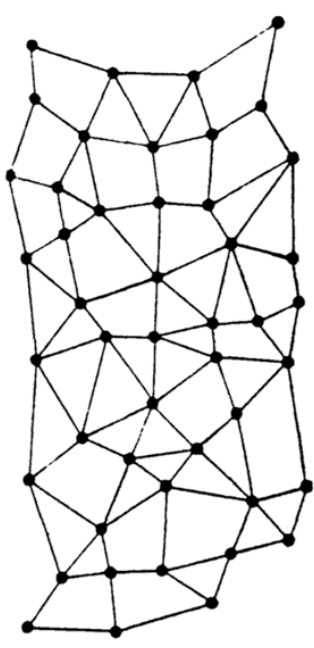

Distributed

Fully Decentralized Distributed

$\mathrm{P} 2 \mathrm{P}$

Figure 1: Centralized, decentralized and distributed networks according to Baran (1964: 1) and revised categories.

This distinction has found wide adoption within the blockchain community, but has become anachronistic. Fundamentally, it does not match current use in computing, and thus creates a series of false impressions (see also Buterin, 2017). Arguably, the names applicable to the second and third diagram should be reversed (Grange, 2016).

In spite of not capturing the distinction between systems that are centralized by design and systems that moved to a degree of centralization from an originally decentralized design, Baran's illustration of a centralized network is not controversial. However, he depicts a decentralized network as one which does have a center, but whose structure or hierarchy is non-concentrated.

Currently, a better understanding for the term "decentralized" is, as the name suggests, a system lacking a (decision-making and SPOF) ${ }^{6}$ center. The Internet is an example of a decentralized system. While there is still no ultimate center, the Internet is also not fully decentralized, as there

\footnotetext{
${ }^{6}$ According to Russian programmer and Ethereum co-founder Vitalik Buterin, to the two aforementioned dimensions of decentralization (political and architectural, respectively) one should add a third one: logical decentralization, namely whether the system's interface looks monolithic or not. "One simple heuristic is: if you cut the system in half, including both providers and users, will both halves continue to fully operate as independent units?" (Buterin, 2017)
} 
are a number of decision-making centers or "hubs" within its structure. Cash transactions, by definition, are almost completely decentralized. Therefore, there is a gradient between the centralized and the fully decentralized, in the middle of which the partly decentralized exists.

Distributed computing is a system in which each independent computer or node (with a local memory) communicates with the others through message-passing. This comes in opposition to the alternative of having one shared memory, i.e., of being a "parallel system," such that the collection of independent nodes appears to the users as a single computer (Tanenbaum and Van Steen, 2007: 2; 2016: 969). For instance, if the customer of a bank notices no difference between doing a transaction in one office of a bank and another one on the other side of the country (despite there being numerous computers in the system, plus a master computer per office and a central computer at the headquarters), it is a distributed system (Tanenbaum and Van Steen, 2007: 3).

What Baran's third diagram shows is not what is currently known as a distributed network, but a purely peer-to-peer $\left(\mathrm{P}_{2} \mathrm{P}\right)$ network. A distributed system may be centralized or decentralized. A $\mathrm{P}_{2} \mathrm{P}$ system is a particular type of distributed system in which the clients also act as servers: They share their hardware resources for other users to access without the need for intermediaries, i.e. they are "servents" (clients + servers) - in contrast to the client/server model .

$A P_{2} P$ system may have a central entity, but if this is the case it is known as hybrid $\mathrm{P}_{2} \mathrm{P}$ system. Pure $\mathrm{P}_{2} \mathrm{P}$ systems are decentralized: the nodes are equipotent and, thus, there are no hubs (Schollmeier, 2001: 101-102). File-sharing mechanisms like Napster and BitTorrent constitute examples of $P_{2} P$ systems. Bitcoin is an example of a P2P system that has ended up forming hubs (mining pools) and thus does not exhibit full decentralization.

In conclusion, as shown by Figure 2, whether a system is decentralized (or centralized), distributed (or parallel) and/or $\mathrm{P}_{2} \mathrm{P}$ (or client/server) depends on the answer to different questions. The anachronism given by the application of Baran's typology misconstrues this as if "centralized," "decentralized" and "distributed" were three possible answers to one common question, which is not the case. 
Classification criteria

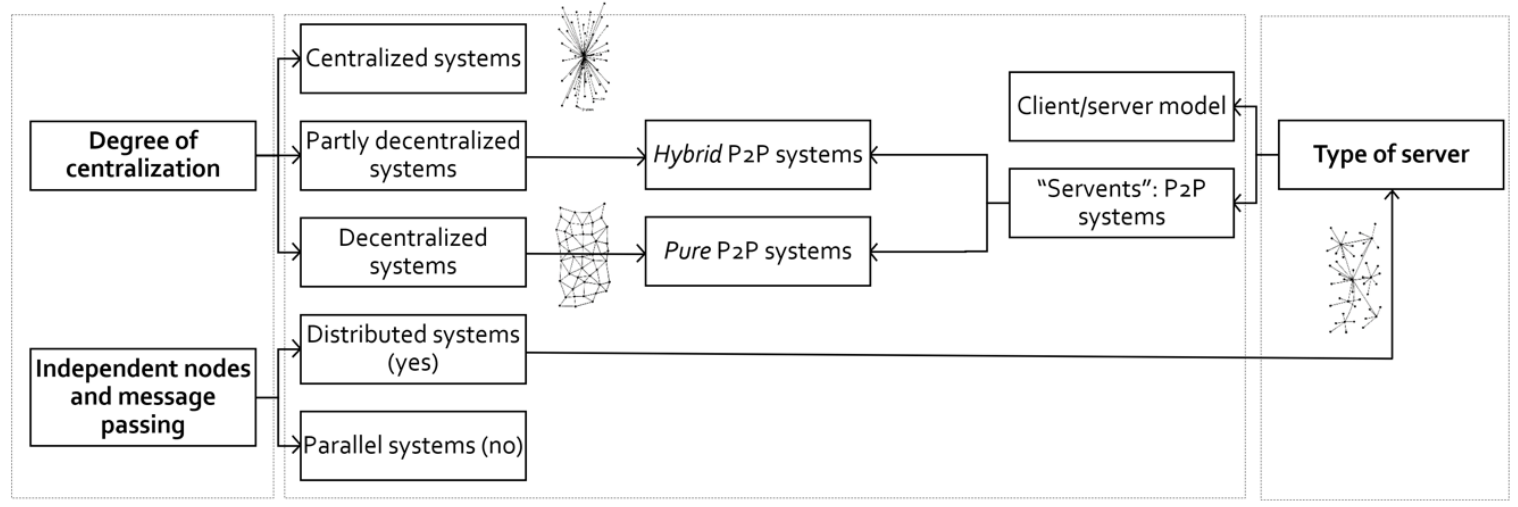

Figure 2: Whether a computing system is centralized, decentralized, distributed or peer-to-peer $(P 2 P)$ constitutes in each case an answer to a different question. The categories should thus not be construed as a continuum.

\subsubsection{The Difference Between Bookkeeping and Accounting}

This paper distinguishes types of triple-entry systems based on whether they merely keep a shared record of transactions, or whether they undertake a more complex processing task on the basis of that information. For this purpose, the distinction between bookkeeping and accounting is used (Ibañez et al, 2020). However, we should note that, the meanings assigned to recordkeeping, bookkeeping and accounting in the literature are not completely homogeneous.

This dispute is difficult to settle because the peer-reviewed literature has not directly dealt with this question -at best, it has deserved a sentence for each term, whereas handbooks and manuals provide definitions outright without justifying them.

While some believe that there is no difference between bookkeeping and accounting (Lomax, 1918: 74), others do. Edwards (1960: 447), for example, claims that recordkeeping would be to preserve the documentary evidence of a particular transaction. Bookkeeping, in turn, would be a historical stage that came after recordkeeping and consists "of analyzing, classifying, and recording transactions." Finally, the ulterior stage of accounting is "bookkeeping with additional refinements of financial summarization and a control function added."

However, the majority position seems to be that bookkeeping and ("mere") recordkeeping are synonyms, whereas accounting "builds on top of bookkeeping to make that information flow to the decision-making areas of the firm, by means of systematizing, compiling, collating, synthesizing, 
processing, analyzing and/or auditing" (Ibañez et al, 2020: 15). This position is found in the peerreviewed literature (Rukhiran and Netinant, 2018; Vollmer, 2003: 357) and in many instruction manuals and handbooks (Chandler, 1977: 109-110; Ge, 2005: 3; Ginigoada Foundation, 2017: 3i Peters-Richardson, 2011: 7; Wild et al, 2011: 4). This is the distinction that we follow. ${ }^{7}$

We find that the suggestion by Grigg (2017b; 2019; see also Ibañez et al, 2020) of importing this distinction to the classification of triple-entry systems allows to apprehend their differences better. It is thus recommendable to differentiate between triple-entry bookkeeping (TEB) and triple-entry accounting (TEA). TEB systems simply record transactions in a triple-entry fashion (e.g. Bitcoin, see Grigg, 2011; Ibañez et al, 2020) and TEA systems involve an accounting software built on a layer of TEB.

\subsubsection{An Accounting Typology for Blockchain-inspired Technology}

With the aforementioned categories clarified, we can proceed to establish a typology that functions as a proper "toolbox" to give an account of the TEA phenomenon. Before explaining triple-entry recordkeeping, we need to understand recordkeeping itself.

Recordkeeping is also known as bookkeeping because the instrument where a firm's transactions with other companies are recorded is called a "book." The book where transaction raw data is first recorded - sequentially - is called a journal. Accounting records are different from bookkeeping records in that transactions are recorded analytically, rather than sequentially: transactions are classified so that the resulting record shows information that is meaningful for business life (for instance, it facilitates decision-making or financial reporting). Thus, the accounting process takes the information of the journal and posts it in a second book, where information is organized analytically. This book is known as ledger. In consequence, accounting happens in ledgers, whereas bookkeeping is limited to journals.

If the two companies who are parties to a transaction use the same book, it is a shared book. It is hard to conceive a shared book on paper. Rather, shared books are held in computer systems

\footnotetext{
${ }^{7}$ In practice, the distinction still leaves some room for debate. One may argue over where the line between accounting and bookkeeping lies, since e.g. when recording a transaction, some classification may be involved, but only through the mechanical application of rules discovered or invented in the accounting profession.
} 
common to (or connected to) both firms. Computer systems may be parallel or distributed. If the book is held on a distributed system, it is a distributed book. If - as a consequence of being unable to trust each other - the computers (nodes) in the system resort to verification techniques to maintain a consensus about the transaction history, the technology for this distributed book receives a particular industry name: Distributed Book Technology (DBT). ${ }^{8}$

If the DBT record is a journal, the system may be called Distributed Journal Technology (DJT). If it is ledger, Distributed Ledger Technology (DLT). ${ }^{9}$ Hence, under a proper usage of accounting terminology, DLT is thus a subtype of DBT, in spite of the former usually being mistaken for the latter, because not all books are ledgers.

A particular subtype of DBT is known as "blockchain." Blockchain's main characteristic is that transaction data is stored in data packages called "blocks" which include cryptographic references to previous blocks, thus forming a chain of blocks. All blockchains are DBT, but not all DBT is blockchained. However, DBT is based on/inspired by blockchain. Therefore, blockchains and DBT are in the same industry category. ${ }^{10}$

\footnotetext{
${ }^{8}$ For examples of usage of the term DBT, see Liu and Xu (2018: 1853).

${ }^{9}$ For works advocating a proper usage of the terms DLT and DJT, see Vagneur (2018), University of Derby (2019) and Shea (2015).

${ }^{10}$ This definition is not shared by all. Odom (personal communication, February 27, 2020), for instance, claims that blockchains and DLT are the same, and that they are necessarily PoW-based decentralized systems: "There is no such actual thing as a "DLT" unless it includes proof-of-work. Any such project without proof-ofwork is actually under centralized control, though it may contain "distributed" elements in its design."
} 




Figure 3: Two representations, from an accounting perspective, of the "family tree" of categories of DLT, the technology to which TEA systems usually resort to (though in principle it is not required).

The typology table (see below) describes these categories in a more systematic manner.

\subsection{THE CONCEPT OF TRIPLE-ENTRY ACCOUNTING}

The purpose of this section is threefold. First, to describe triple-entry accounting as a threedimensional accounting device which comes to address certain problems in traditional, redundant, double-entry accounting (as it was originally described by Todd Boyle). Second, we define what triple-entry accounting is. Third, we enumerate the essential and nonessential features of a TEA system. 


\subsubsection{Three-dimensional Accounting}

Whether triple-entry or not, shared ledgers enable three-dimensional accounting.

There are two parties to a transaction, but the transaction is only one. Yet, traditionally, the parties keep independent and mirroring records of the same economic event. In other words, there are two records for each one transaction. A sale, for instance, is "recorded into receivables by a seller, (...) [and] as a purchase, into accounts payable by a buyer" (Boyle, 200ob). Furthermore, each party records the transaction in a double-entry manner. "That's quadruple entry. Since every transaction in the developed world also causes quadruple entries when it clears [through] a bank, that's octuple entry" (Boyle, 200ob; italics are ours). We can call this "redundant bookkeeping."

Any triple-entry system is an inter-party bookkeeping system which eliminates this redundancy: There is a shared transaction repository keeping a single record of the transaction. Boyle (2003a, 2003k, see also Ibañez et al, 2020) explains that, in this context, bookkeeping becomes at least three-dimensional, because there is a need to represent transactions from the viewpoint of its two parties (even if stored in a viewpoint-independent manner): the sending side and the receiving side. Attempts at representing three dimensions in two dimensions will necessarily result in redundancy, that is, recording the same transaction over and over (e.g. different, mirroring books for each party to the transaction). Historically, 3D accounting records were not available. At present, however, computer-based shared ledgers can maintain a shared record in a three-dimensional manner. Ibañez et al (2020) provide a representation of three-dimensional ${ }^{11}$ accounting as explained above, in Figure 4 .

\footnotetext{
${ }^{11}$ More dimensions can be added, resulting in a hypercube (Boyle, 2003a).
} 


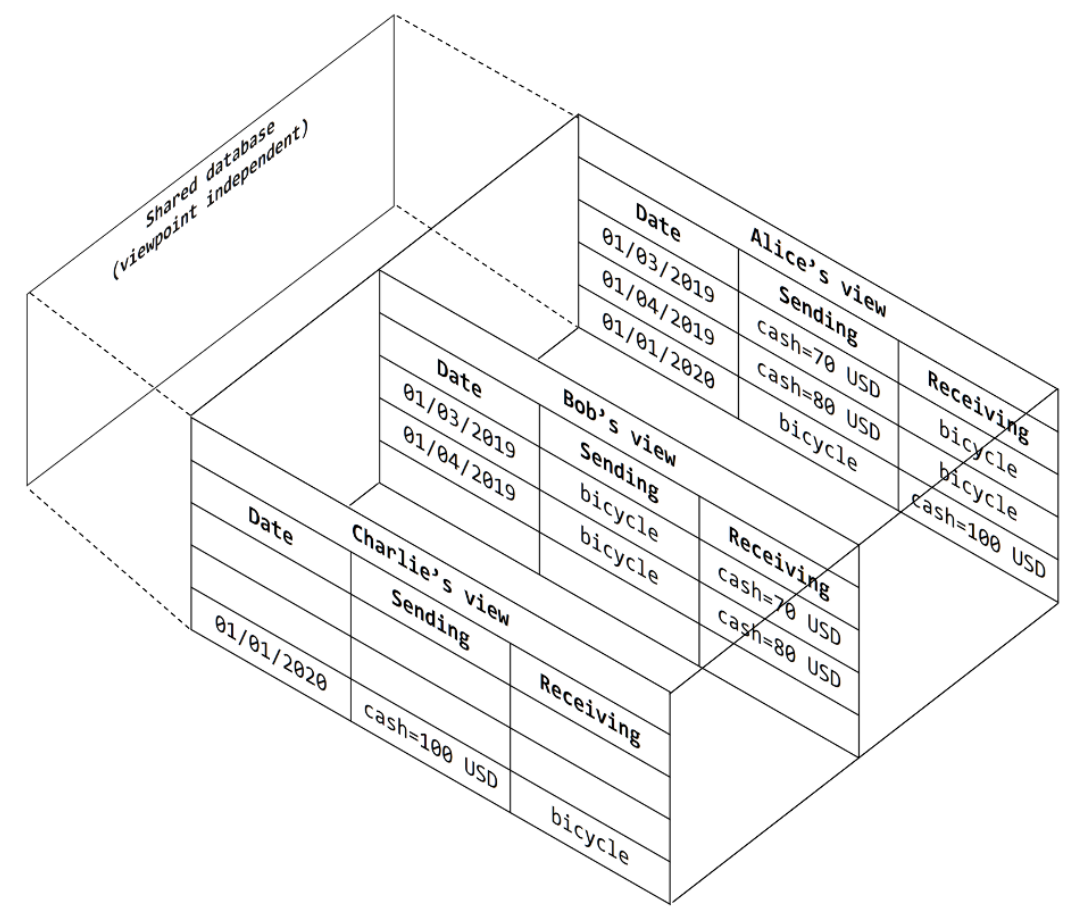

Figure 4: Three-dimensional accounting, in which N sheets equal the N parties to the system (Ibañez et al, 2020; based on Boyle, 2003a, 2003k).

\subsubsection{Triple-entry Accounting: A Concept}

Triple-entry bookkeeping is a particular proposal for a shared transaction record (and thus, for $3^{D}$ accounting). It relies on triple-signed receipts to reach an agreement on the content of the shared record. As explained by Ibañez et al (2020: 6):

"In order to update the shared record with a new transaction record, two parties need to be involved: one initiates a transaction entry - called "request," "offer" or "transaction draft" - and the other accepts it. This can be seen as a signature-gathering process: one party adds their signature to the transaction entry draft and the counterparty accepts by countersigning, before the entry gets processed by the STR which can be a middleware server or a distributed ledger; the STR checks the validity of the signatures and then, if everything is in order, signs off on the entry (...). This generates a hashed triple-signed receipt, such that all the parties hold the same data that 
cannot be manipulated or lost: a single, shared entry serving as the single source of truth."

The two fathers of triple-entry bookkeeping, lan Grigg and Todd Boyle, conceived this sort of threepronged consensus mechanism. However, it is worth noting that only Grigg named the system "triple-entry" because of the tripartite consensus involving three signed messages (Grigg 2005; Ibañez et al, 2020). Boyle (2001) called it in this manner because he had envisioned two (optional) private transaction stubs on top of the shared entry for the parties to insert nonessential data. ${ }^{12}$

As anticipated, based on the prior distinction between bookkeeping and accounting, we can conceive something beyond a "mere" shared record of transactions: A triple-entry system with an accounting solution. This constitutes triple-entry accounting (TEA). TEB requires a shared journal, whereas TEA requires a shared ledger. Given that accounting presupposes bookkeeping, but the reverse is not true, all TEA systems are TEB systems, but not all TEB systems have an accounting layer.

Note that a TEA system is not bound to any particular technology, but most current TEA systems resort to DLT. Bitcoin is a well-known triple-entry system using DBT, but since it does not have an accounting layer, it is not TEA and does not involve a distributed ledger. Strictly speaking, it is a TEB system with DJT technology.

Furthermore, note that the three entries in TEA are not three mirroring records of a transaction., but three signature entries or signed messages. This means that TEA records may be compatible with both a single-entry and a double-entry representation of transactions. ${ }^{13}$

\footnotetext{
${ }^{12}$ For a discussion of the many possible meanings of the word "entry" and whether TEA should be called "single-entry" instead of "triple-entry," see lbañez et al (2020).

${ }^{13}$ For a more detailed discussion of the polysemy of the term "entry," see Ibañez et al (2020).
} 

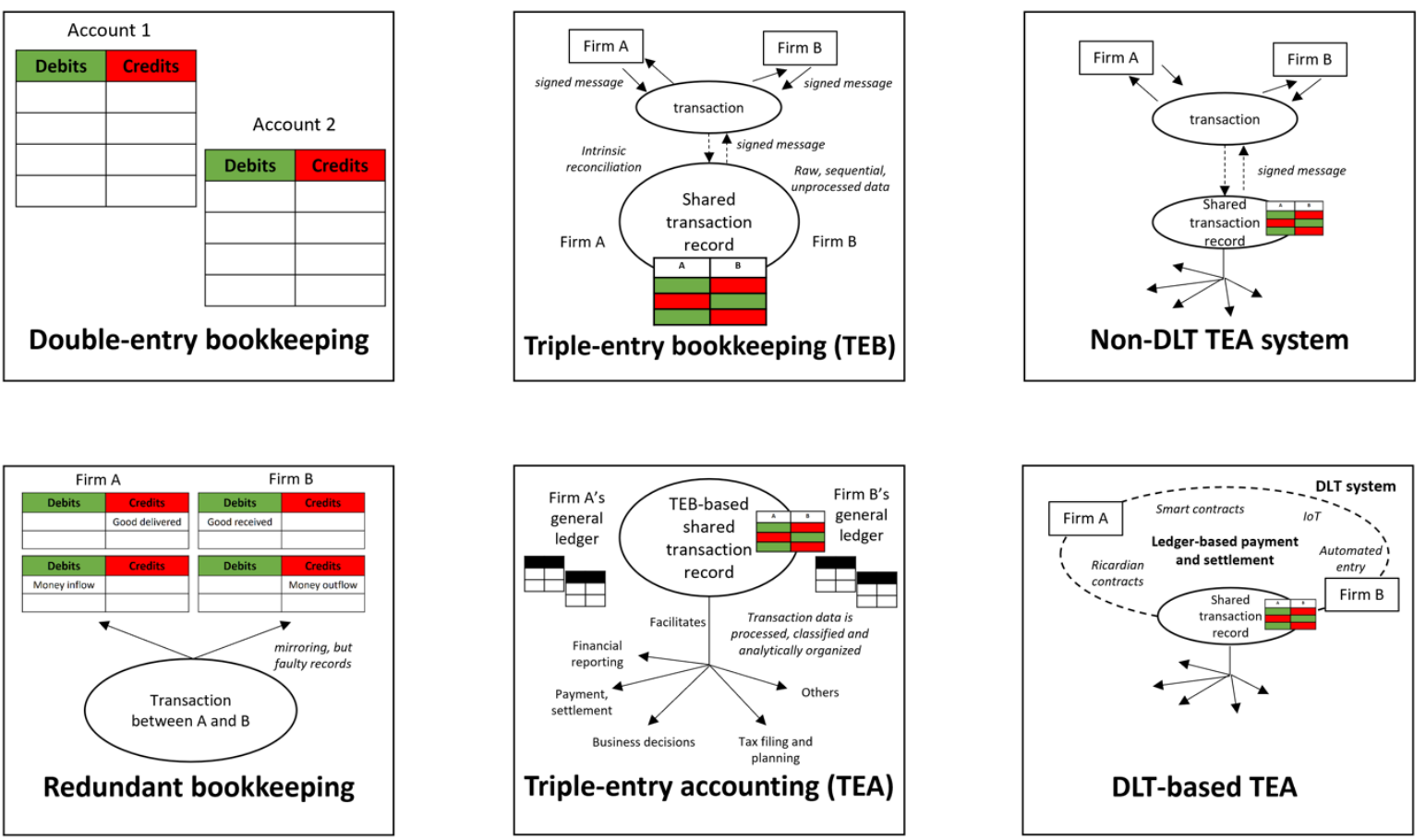

Figure 5: DLT-based TEA systems in comparison with other categories. Note that TEA systems not only record, but also enable the transaction, that the record is shared between the parties (intrinsic reconciliation, unlike traditional, redundant bookkeeping), and that transaction data is processed and organized to facilitate business life.

\subsubsection{Criteria for TEA}

With the categories discussed in the previous subsection in mind, we can establish that a TEA system has intrinsic requisites and two near-essential features, numbered below. Furthermore, we have identified fourteen important characteristics that a TEA system may have, in spite of them not being definitionally essential.

\subsection{TEA - Operational Criteria}

a. Shared transaction record (single truth): a TEA system keeps a record of the transactions between two or more unrelated parties in a shared journal or ledger. This condition is informed by the What You See Is What I See (WYSIWIS) principle. ${ }^{14}$

\footnotetext{
${ }^{14}$ The WYSIWIS principle does not preclude the possibility of restricted viewing permissions, as long as the information that both parties have still emerged from a central, shared record.
} 
b. Offer-acceptance-validation structure: through three signed messages resulting in a triplesigned receipt.

c. Ledger / accounting layer: transactions should not just be recorded in an unprocessed manner. Raw transaction data should be fed to each party's general ledger or it should be processed in such a way that it facilitates corporate life (decision-making, financial analysis and forecasting, invoicing, tax planning, financial reporting...).

\subsection{Near-essential features}

a. Immutability of transactions: while a shared record solves the problem of redundant/duplicate records, it creates a security challenge (on top of the pre-existing possibility of tampering). This is the need to trust that the other party will not alter the dominating record in their favor. Immutability of transactions fixes this problem. In principle, a TEA system without this security feature is conceivable. However, Grigg's three-way consensus through digitally signed receipts ensures immutability by design. Furthermore, the low degree of trust characterizing businesses since before the first double-entry systems, makes the immutability of the shared record of transactions such a practical imperative that it can be regarded as an essential requisite. This has historically been the case. ${ }^{15}$

Note that since no system can be regarded to be absolutely immutable, the word 'immutability' should be applied within reasonable bounds to systems that are significantly harder to modify than their competitors.

b. Strong digital identity verification: just like the immutability trait, or the digital character of the system, strong digital identity verification ${ }^{16}$ is a necessary security feature for a TEA system to be sufficiently reliable and practical.

\footnotetext{
${ }^{15}$ lan Grigg (2005) called for a secure, "reliable," "bullet proof accounting system," to "keep a record safe" from unconsented changes, fraud and theft. "Computer science introduces concepts such as transactions, which are defined as units of work that are atomic, consistent, isolated, and durable" (Grigg, 2005, italics are ours). Todd Boyle (2000e) also stated that the economics of a Public Transaction Record depend on achieving security, which is why he proposed a "true, unforgeable record". See also Pacio (2019b).

${ }^{16}$ A TEA system requires at least an alias, which means it cannot be a completely anonymous system (Boyle, 2003j). According to Boyle (2003h), this is also a requisite to comply with anti-terrorism and anti-money laundering legislation.
} 


\subsection{Architectural add-ons}

a. Network-based settlement/payment: in theory, a TEA system can function as an archive, recording transactions common to two or more parties that conduct their dealings elsewhere. However, if the network both enables and records payment, an enhancement in efficiency may be achieved (Boyle, 1999; 2001f; 2003b).

b. Smart contracts-enabling network: network-based settlement/payment does not presuppose smart contracts, but the latter might enhance the appeal of the former by making the network more versatile. Furthermore, smart contracts may play a role in automating accounting practices (Ibañez et al, 2020).

c. Ricardian contract-enabling network: neither network-based settlement/payment nor smart contracts imply Ricardian contracts, but the latter might enhance the appeal of the former by improving the legal standing of network-based transactions.

d. Distributed Ledger (more than one node): the shared ledger is set up on a system of distributed computing, i.e. with independent nodes communicating through message passing.

- DLT: the distributed ledger is a decentralized, blockchained or blockchain-inspired system for nodes lacking mutual trust.

- Blockchain (permissioned or otherwise): a blockchain is not necessary to enable, notify, store and timestamp transactions. However, it might prove to be the most efficient method to do all of the above.

e. "Stub - shared entry - stub" structure: to enable the recording of non-essential information. ${ }^{17}$

f. General ledger for transactions: a TEA system need not involve a master record of a firm's transactions. Nevertheless, if it did so, the system would be in a position to compete with other general ledger software accounting solutions.

g. General ledger for reporting: to facilitate financial reporting, tax reporting, sales reporting etc. is not an essential feature of a TEA system, but its presence may improve the system's appeal.

h. Viewing permissions: a TEA repository with recorded transactions may be public (e.g. gossip protocols) or private. A private TEA could e.g. be encrypted, only allowing people

\footnotetext{
${ }^{17}$ Alternatively, a TEA system may only have the shared entry. This structure is expected from REA-inspired systems.
} 
with access rights to view the transactions (Boyle, 2000c; 2001b; 2003b; 2003e). However, making this optional for each transaction, "according to entity preference," would improve the appeal of the TEA system (Pacio, 2019b: 3).

\subsection{Further features}

a. Scalability and high throughput: to be viable to meet business needs in the modern world (Barrit et al, 2019; Pacio, 2019b: 3).

b. Compliance with financial regulations: to improve the appeal of the system (Pacio, 2019b: 3).

C. Affordability: so that even small businesses can use the system (Auditchain, 2018; Pacio, 2019b: 3).

d. User-friendliness: so that even small businesses can use the system (Boyle, 2000a; Hildebrand, 2020; Pacio, 2019b: 3).

\subsection{TyPology TABLE}

Having defined triple-entry accounting and explicated the concepts necessary to apprehend the specificity of the notion and its implementation, we can proceed to summarize the fundamental taxonomy of TEA.

\begin{tabular}{|l|l|}
\hline Book & A record of transactions. It may be either a journal or a ledger. \\
\hline Journal & $\begin{array}{l}\text { The book of first entry where raw (unprocessed) transaction data is } \\
\text { recorded sequentially. }\end{array}$ \\
\hline Ledger & $\begin{array}{l}\text { The book of second/final entry to which the transactions recorded in a } \\
\text { journal are processed and imported ("posted"), but in an analytical } \\
\text { order. }\end{array}$ \\
\hline General Ledger & $\begin{array}{l}\text { A master collection of books containing all of a company's transactions } \\
\text { (usually in a summarized form, as subsidiary ledgers - subledgers - }\end{array}$ \\
\hline
\end{tabular}




\begin{tabular}{|c|c|}
\hline & $\begin{array}{l}\text { contain the details). It is the central transaction repository. In software } \\
\text { applications, this repository is often split in two modules (Boyle, 2003g): } \\
\text { - the General Ledger for Transactions (GLT), where objectively } \\
\text { verifiable transaction data is posted; } \\
\text { - The General Ledger for Reporting (GLR), where the architecture } \\
\text { of the ledger is reorganized through subjective adjustments to } \\
\text { serve downstream integration and reporting requirements. }\end{array}$ \\
\hline Shared Book & A shared journal or shared ledger. \\
\hline Shared Journal & $\begin{array}{l}\text { A journal maintaining transaction records for two or more unrelated } \\
\text { parties. }\end{array}$ \\
\hline Shared Ledger & $\begin{array}{l}\text { A ledger maintaining transaction records for two or more unrelated } \\
\text { parties. }\end{array}$ \\
\hline $\begin{array}{l}\text { Shared Transaction } \\
\text { Repository (STR) }{ }^{18}\end{array}$ & 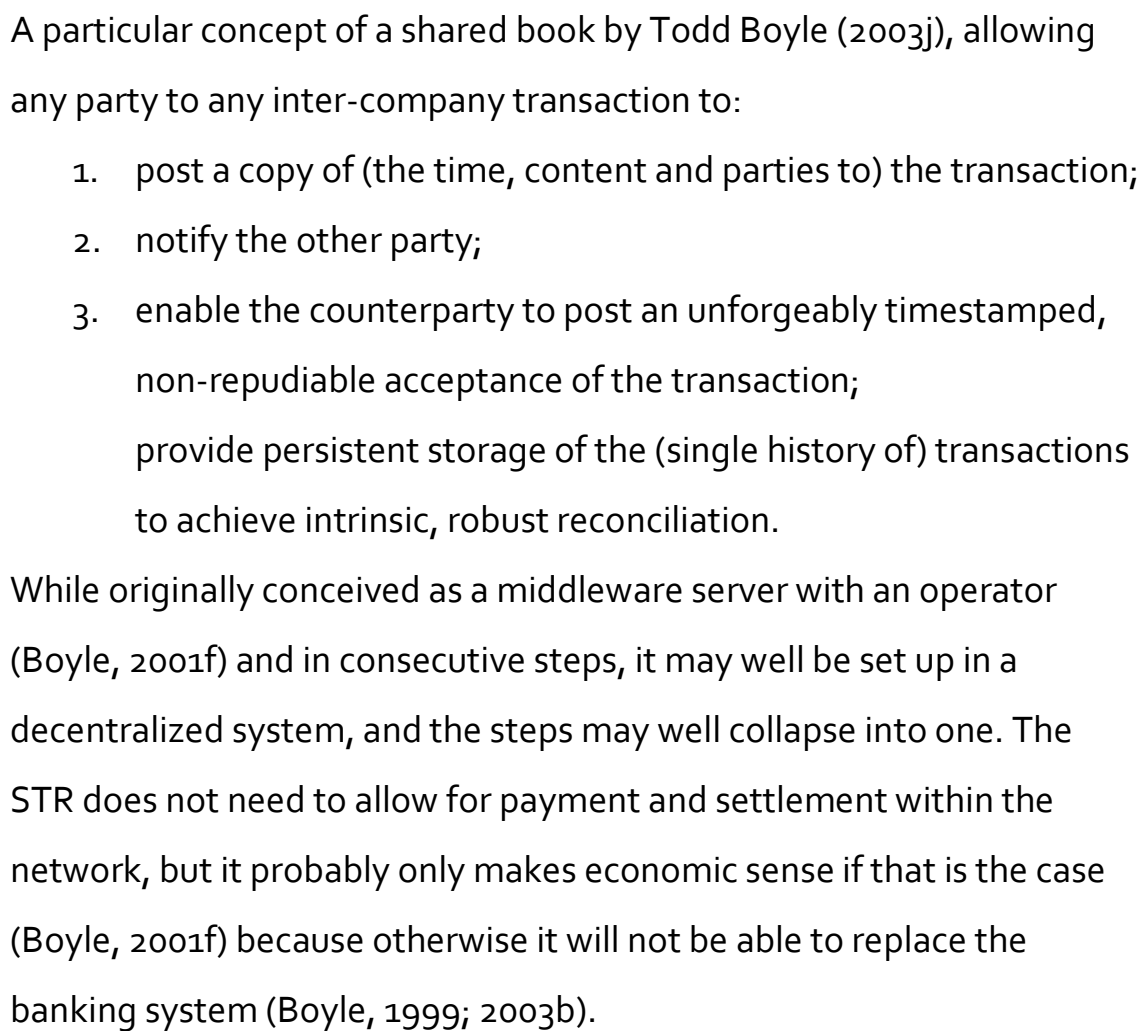 \\
\hline
\end{tabular}

${ }^{18}$ Originally named 'public transaction repository' or PTR (Boyle, 2000e). 


\begin{tabular}{|c|c|}
\hline Distributed Book & $\begin{array}{l}\text { A journal (transactions are unprocessed and sequentially organized) or } \\
\text { ledger (transactions are processed, consolidated and analytically } \\
\text { organized) set up on a network of computers conforming to a } \\
\text { distributed system (instead of a parallel system). } \\
\text { For both distributed journals and distributed ledgers, the distributed } \\
\text { database may be, in order of decentralization: }{ }^{19} \\
\text { 1. a traditional database in which a computer stores a master } \\
\text { database which then duplicated through the network (in discrete } \\
\text { intervals), requiring trust on all the nodes, i.e. in the network } \\
\text { operator; } \\
\text { 2. a traditional database in which specialized software tracks } \\
\text { changes over all the databases and replicates them across the } \\
\text { network (on an ongoing basis), requiring trust on all the nodes, } \\
\text { i.e. in the network operator; } \\
\text { 3. a DBT system. }\end{array}$ \\
\hline $\begin{array}{l}\text { Distributed Book } \\
\text { Technology (DBT) }\end{array}$ & $\begin{array}{l}\text { An industry term for a particular kind of distributed book--usually either } \\
\text { blockchain or blockchain-inspired technology: a record of transactions } \\
\text { stored in a database set up over a network of computers/nodes which } \\
\text { cannot trust each other (Brown, 2016), }{ }^{20} \text { and thus resort to } \\
\text { verification/validation (and time-stamping with unique cryptographic } \\
\text { signatures) to maintain a consensus }{ }^{21} \text { about (the single set of) shared } \\
\text { facts. In other words, the network operator does not maintain the } \\
\text { records by itself (it is not "central"). }\end{array}$ \\
\hline
\end{tabular}

\footnotetext{
${ }^{19}$ See also Grig (2016d): "Todd Boyle's concept could not work without a server, a quorum or a blockchain."

${ }^{20}$ One could further distinguish between fully trustless DBT systems and walled garden DBT systems with a gatekeeper (Grigg, 2017: 3).

${ }^{21}$ Trust and consensus solve are ways to work around the "what you see is what I see" problem, known by the WYSIWIS acronym.
} 


\begin{tabular}{|c|c|}
\hline $\begin{array}{l}\text { Distributed Journal } \\
\text { Technology (DJT) }\end{array}$ & $\begin{array}{l}\text { A DBT system storing raw transaction data, sequentially and in a } \\
\text { journal. }\end{array}$ \\
\hline $\begin{array}{l}\text { Distributed Ledger } \\
\text { Technology (DLT) }\end{array}$ & $\begin{array}{l}\text { A DBT system going beyond first entry to processing, consolidating and } \\
\text { organizing transactions, i.e. a DBT system with a ledger instead of a } \\
\text { journal. } \\
\text { The term DLT is often incorrectly applied to DJTs, despite there being } \\
\text { no shared ledger, but only a shared journal. }\end{array}$ \\
\hline Blockchain & 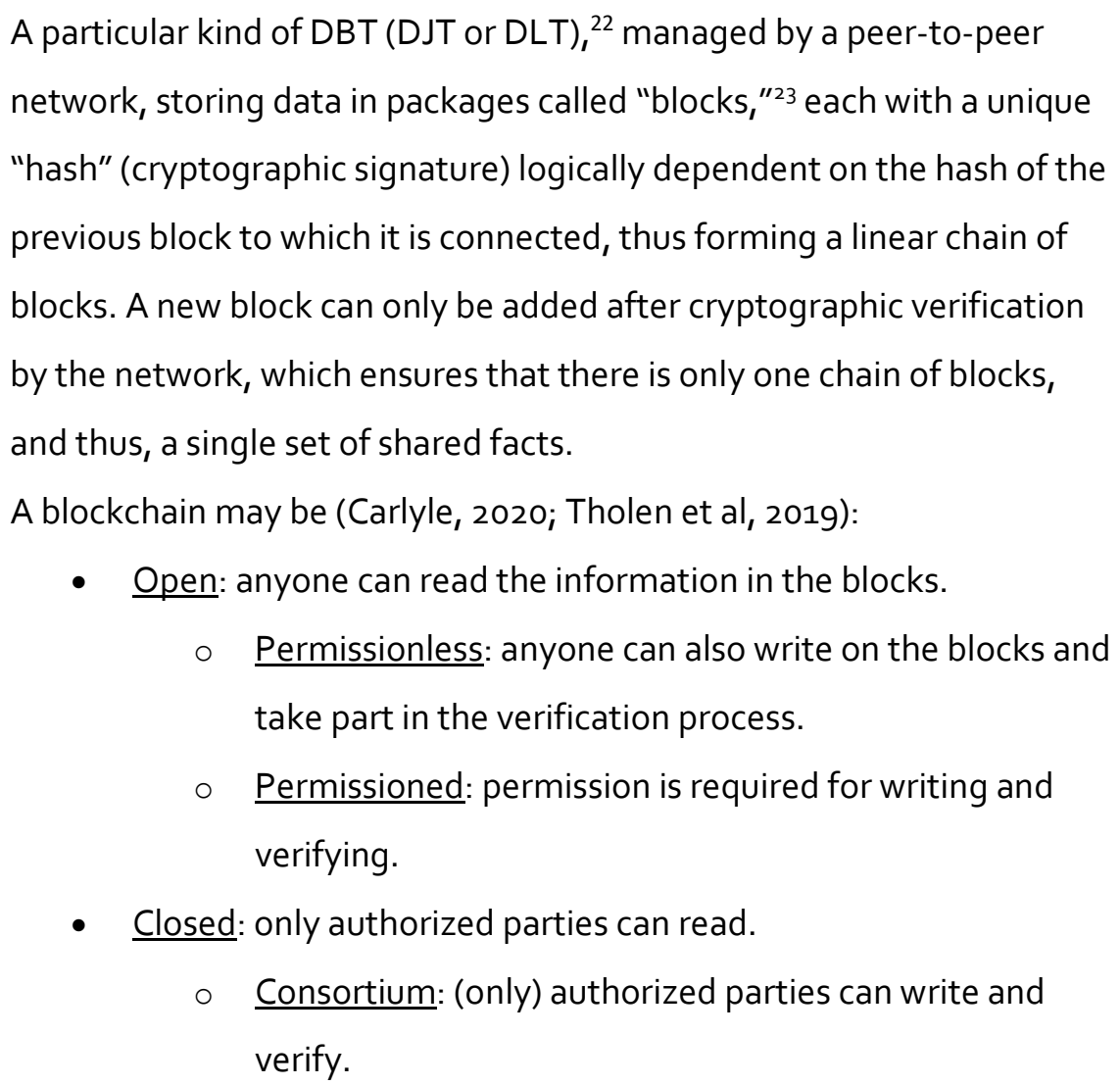 \\
\hline
\end{tabular}

\footnotetext{
${ }^{22}$ Using the terms 'blockchain' and ' $\mathrm{DLT}$ ' interchangeably is a common practice. Many choose to do this in spite of being aware of the distinction, in order to conform to popular usage (Aste et al, 2017: 19-20; Tholen et al, 2019: 7). We do not do this. Instead, we always stick to the specific meaning of each term (except in literal quotes).

${ }^{23}$ In Proof-of-Work systems such as Bitcoin, a block includes a concatenation of transactions (the set is determined by the wish of the miner seeking to verify that set of transactions), the answer to a cryptographic puzzle called "nonce," and the hash.
} 


\begin{tabular}{|c|c|}
\hline & $\begin{array}{l}\text { Private permissioned or "enterprise": only the network } \\
\text { operator can write and verify. }\end{array}$ \\
\hline $\begin{array}{l}\text { Triple-entry } \\
\text { Bookkeeping (TEB) }\end{array}$ & $\begin{array}{l}\text { Shared book in which there is an "offer - acceptance - validation" or } \\
\text { "signature - signature - signature" design. }{ }^{24} \text { Recordkeeping is } \\
\text { sequential and journalized. Todd Boyle's STR and Ian Grigg's Ricardo } \\
\text { Payment System are examples of TEB. }\end{array}$ \\
\hline $\begin{array}{l}\text { Triple-entry } \\
\text { Accounting (TEA) }\end{array}$ & $\begin{array}{l}\text { A TEB system with an accounting layer, i.e. at least one of the following } \\
\text { two characteristics: } \\
\text { - The STR is not limited to just sequentially storing transactions, } \\
\text { but also to classifying and interpreting them, facilitating } \\
\text { decision-making, financial analysis and forecasting, tax planning } \\
\text { and financial reporting. }{ }^{25} \\
\text { As in Boyle's (2003j) original formulation, the STR serves as a } \\
\text { subledger for each of both parties to a transaction's general } \\
\text { ledger: both general ledgers retrieve the transaction data from } \\
\text { the STR. } \\
\text { It involves a shared ledger underpinned by triple-signed receipts formed } \\
\text { through offer, acceptance and validation. }\end{array}$ \\
\hline Bitcoin & $\begin{array}{l}\text { A (currently hybrid) P2P payment system constituting both a } \\
\text { permissionless public blockchain and an "asynchronous" TEB system } \\
\text { (Ibañez et al, 2020) without an accounting layer. }\end{array}$ \\
\hline $\begin{array}{l}\text { Resources, Events, } \\
\text { Agents (REA) }\end{array}$ & $\begin{array}{l}\text { An ontology }{ }^{26} \text { for an accounting system which replaces the classical } \\
\text { double-entry system with an information system integrated to all }\end{array}$ \\
\hline
\end{tabular}

${ }^{24}$ Note that Todd Boyle's (2003e; 2003g) TEA included an offer - acceptance - validation structure, but assigned the term "triple-entry" not because of it but because of the "stub - shared entry - stub" structure of each shared transaction file.

${ }^{25}$ While "bookkeeping" consists in recording transactions, "accounting" consists in all of the above.

26 "A number of abstractions that generalize business events" (Boyle, 2000b). 


\begin{tabular}{|c|c|}
\hline & $\begin{array}{l}\text { functional areas of an enterprise, not just limited to the accounting } \\
\text { department). For this purpose, it proposes a single, shared record of } \\
\text { transactions. When applied to inter-company transactions, }{ }^{27} \text { it is } \\
\text { compatible with TEA and may even serve to supplement TEA, to which } \\
\text { it is genealogically related (Ibañez et al). }\end{array}$ \\
\hline $\begin{array}{l}\text { Open-edi } \\
\text { Distributed } \\
\text { Business } \\
\text { Transaction } \\
\text { Repository } \\
\text { (OeDBTR) }\end{array}$ & $\begin{array}{l}\text { A term within the REA ontology for a single-entry system which tracks } \\
\text { the immutable history of changes triggering changes of state in multiple } \\
\text { business entities, relying on the independent view of the transaction as } \\
\text { a single source of truth and the open-edi electronic data interchange } \\
\text { standard (McCarthy and Holman, 2019). } \\
\text { An OeDBTR does not require DLT, but DLT "exhibits all of the principles } \\
\text { of the distributed repository in which to store business transactions" } \\
\text { (Holman, 2019). }\end{array}$ \\
\hline $\begin{array}{l}\text { Momentum } \\
\text { accounting }\end{array}$ & $\begin{array}{l}\text { An accounting system which, aside from wealth and income (the rate of } \\
\text { change in wealth), records the rate of change in income. Its inventor, } \\
\text { Yuji ljiri (1982), named it "triple-entry bookkeeping" }{ }^{28} \text { but it is really } \\
\text { accounting (Grigg, 2017b, 2019). Despite other works of ljiri that had an } \\
\text { indirect impact on the TEA concept discussed in this paper, momentum } \\
\text { accounting is almost unrelated to it (Ibañez et al, 2020). }\end{array}$ \\
\hline Russian triple-entry & $\begin{array}{l}\text { Also known as "triple-book system," it is an accounting system which } \\
\text { proposes a continuous update of inventory and the usage of only three } \\
\text { books: capital book, systematic accounts book and balance book (Faccia } \\
\text { et al, 2020; Victorovna, 2015). It is unrelated to TEA. }\end{array}$ \\
\hline Signature & Any token that attests an agreement at a particular point in time. \\
\hline
\end{tabular}

\footnotetext{
${ }^{27}$ REA was mainly conceived for intra-business organization, but is applicable to inter-company transactions. A number of works have developed this possibility, applying it to supply chain management (Haugen and McCarthy, 2000).

${ }^{28}$ At present, both ljiri's and Grigg's notions of triple-entry are used, but Grigg's definition has found wider adoption (Gröblacher and Mizdraković, 2019: 60), particularly in cryptographic circles.
} 


\subsection{OTHER DOUBLE-entRY ACCOUNTING ITERATIONS}

A number of other digital means seek to enhance conventional double entry accounting and are worth mentioning:

\subsubsection{Immutable Double-entry Accounting (IDEA)}

The company Pacio (2020: 7) has proposed a concept of blockchain-based double entry accounting adding a layer of immutability to CDEA. It would constitute a better fit than TEA for "single entry counterparty (inter-entity) transactions," which "do not cover the internal transactions such as depreciation, payroll, etc." (ibid: 5). ${ }^{29}$ IDEA is different from other DLT-based accounting services in that the system should be "readily upgradeable to TEA," so as to serve as an interim step to it. This requires the ability to scale.

\subsubsection{Plain Text Accounting (PTA)}

PTA is a type of accounting software aimed at making accounting less convoluted, more accessible, more easily understood and less subject to intellectual property constraint. It gets its name from the fact that it relies on plain .txt files -- rather than, e.g. SOL files. In order to achieve this, accounting data is stored in a simplified and human-readable way (Michael, 2019).

PTA has a number of relations to TEA. First, some of its advocates maintain that PTA is a necessary (or preferable) prior step to TEA and DLT. To "move accounting to the blockchain at this point when everyone is still using CSV files and the proprietary software of large (...) corporations (eg. Quickbooks and Intuit) is premature. We need a common open standard first and to then build tools around that. (...) Before blockchains can/should be used for accounting in the triple-entry form, we should have a common standard for double entry bookkeeping that is in plain text" (Buchman, 2020).

\footnotetext{
${ }^{29}$ That accounting for depreciation may need to be regarded as an issue separate from TEA might have been hinted by Boyle (200ob), who suggested that the e-commerce community could "leave out the accruals, depreciation and other stuff not needed" and instead focus on the shared transaction record.
} 
Furthermore, just like TEA and REA advocates, PTA advocates point out that CDEA is viewpointdependent: it only includes the partial view of a transaction of the party owning the ledger. This means that in order to "model the finances of several entities simultaneously," redundant entries are needed. The PTA tool "Transity," for example, allows the automatic change of viewpoints for each of the parties modelled, which constitutes a partial workaround (Sieber, 2018).

\section{CONCLUSION}

Triple-entry accounting is one of the most innovative concepts at the forefront of blockchain research. Its historical influence is remarkable (Ibañez et al, 2020) and potential efficiency effects are copious. At present, numerous companies compete to win the race toward the development of a widely-adopted, blockchain-based TEA system. However, the taxonomical deficit characterizing this field of research impedes apprehension of what TEA even is.

Due to insufficient usage of accounting vocabulary in blockchain research, it is often unclear what "three entries" means in this context, whether Bitcoin is a TEA system, what the difference is between Bitcoin and a triple-entry accounting software, whether blockchains are necessarily TEA or viceversa and why, if TEA is a proposal for a shared ledger system, TEA records are different from other shared ledgers. This further reveals that the terms "shared ledger," "distributed ledger," "decentralized ledger" and "distributed technology" are often used imprecisely, creating difficulties for the understanding of the underlying technologies.

With the aim of filling this gap, in this paper we set out to achieve a number of goals. First, we create a typology that allows us to give a proper account of the TEA phenomenon. Notably, we lay out the basic characteristics of a TEA system. We also distinguish "bare" triple-entry systems or triple-entry bookkeeping systems (such as Bitcoin), from triple-entry accounting systems. While the TEA systems reviewed are DLT-based, we further distinguish DLT technology from basic DJT technology (again, the Bitcoin example). As a prior step, we also argue against the widely used distinction of centralized, decentralized and distributed authored by Baran.

Our work constitutes an early-stage approximation, shedding light on the conceptual and linguistical complexities surrounding the emergent technology of triple-entry accounting. 
Although aware of the preliminary character of our typology, we hope that it will constitute a useful contribution to the ongoing efforts in the field of TEA and blockchain technology. 


\section{REFERENCES}

AB (2018) "Accounting Blockchain Whitepaper." Accounting Blockchain Whitepaper. Available at https://portal.theaccountingblockchain.io/pdfs/whitepaper.pdf (10/01/2020)

Aste, T.; Tasca, P.; Di Matteo, T. (2017) "Blockchain Technologies: The Foreseeable Impact on Society and Industry." Computer, 50(9), 18-28.

Auditchain (2018) "Auditchain: Decentralized Continuous Audit \& Reporting Protocol Ecosystem." Auditchain Whitepaper. Available at https://auditchain.com/Auditchain-Whitepaper.pdf (10/01/2020)

Auditchain (2019) "Jason Meyers." Auditchain. Available at https://auditchain.com/jason-meyers/ (28/01/2020)

Ballandies, M. C. ; Dapp, M. M. ; Pournaras, E. (2018) «Decrypting Distributed Ledger DesignTaxonomy, Classification and Blockchain Community Evaluation." arXiv preprint, $\operatorname{arXiv:1811.03419.}$

Baran, P. (1964) "On Distributed Communications Networks." IEEE transactions on Communications Systems, 12(1), 1-9.

Barrit, J.; Sheth, S.; Vile, A. (2019) "From PoC to Production: Implementing an Enterprise Blockchain Solution." Vakt and ThoughtWorks. Available at https://files.thoughtworks.com/pdfs/vakt-tw-poc-to-production.pdf (29/01/2020)

Beinke, J. H.; Nguyen, D.; Teuteberg, F. (2018) "Towards a Business Model Taxonomy of Startups in the Finance Sector Using Blockchain."

Boyle, T. (1999) "Differentiating between web-based GLs." GL Dialtone. Available at https://linas.org/mirrors/www.gldialtone.com/2001.07.14/journalbus.htm (22/01/2020)

Boyle, T. (2000a) "CDEA General Ledger Schema." Ledgerism. Available at https://web.archive.org/web/20071001201740/http://www.ledgerism.net/GLSchema1.txt $(17 / 01 / 2020)$ 
Boyle, T. (2000b) "Draft Schema for General Ledger." Ledgerism. Available at http://web.archive.org/web/20051003224536/http://ledgerism.net/GLSchemaDraft1.txt $(08 / 02 / 2020)$

Boyle, T. (2000c) "FAQ." GL Dialtone. Available at http://web.archive.org/web/20000827165329/http://www.gldialtone.com/PTR-FAQ.txt $(11 / 02 / 2020)$

Boyle, T. (2000e) "The Public Transaction Repository (PTR) project." GL Dialtone. Available at http://web.archive.org/web/20000622133330/http://www.gldialtone.com/PTR.htm $(17 / 01 / 2020)$

Boyle, T. (2000g) "WebLedger Architectures; Ending Data Duplication." GL Dialtone. Available at http://web.archive.org/web/20000829141221/http://www.gldialtone.com/endredundancy htm (17/01/2020)

Boyle, T. (2001b) "RE: Initial Draft of CPP-CPA Specification." Available at http://lists.ebxml.org/archives/ebxml-bp/200101/msgooo8g.html (17/01/2020)

Boyle, T. (2001f) "The Shared Transaction Repository (STR) ver. o.6o spec." GL Dialtone. Available at http://linas.org/mirrors/www.gldialtone.com/2001.07.14/STR.htm (17/01/2020)

Boyle, T. (2003a) "Accounting Hypercubes on the Internet." Ledgerism. Available at http://web.archive.org/web/20060102014117/http://www.ledgerism.net/hypercub.htm $(11 / 02 / 2020)$

Boyle, T. (2003b) "The AR/AP Cloud." Ledgerism. Available at http://web.archive.org/web/20060101213250/http://www.ledgerism.net/arapcloud.htm $(11 / 02 / 2020)$

Boyle, T. (2003e) "File-Based Commerce (FBC) Architecture ver. $0.31 \mathrm{spec}$. Business Requirements Viewpoint." Ledgerism. Available at http://web.archive.org/web/20050211111755/http://ledgerism.net/fbc.htm (08/02/2020)

Boyle, T. (2003g) "GLT and GLR: Component Architecture for General Ledgers." GL Dialtone. Available at https://linas.org/mirrors/www.gldialtone.com/2001.07.14/GLT-GLR.htm 
Boyle, T. (2003h) "Ledger Ontology." Ledgerism. Available at http://web.archive.org/web/20080209023044/http://ledgerism.net:80/LedgerOntology.ht $\underline{\mathrm{m}}(11 / 02 / 2020)$

Boyle, T. (2003j) "Shared Transaction Repository (STR) ... a High Level Software Specification." Ledgerism. Available at http://web.archive.org/web/20060102052824/http://www.ledgerism.net/STR.htm $(17 / 01 / 2020)$

Boyle, T. (2003k) "The Argument to Abolish Double-Entry Accounting and Abolish the Assets=Liabilities + Owner's Equity Equation." Ledgerism. Available at http://web.archive.org/web/20031208235246/http://ledgerism.net/GLSchema2.txt $(08 / 02 / 2020)$

Brown, R. G. (2016) "On Distributed Databases and Distributed Ledgers." Richard Gendal Brown: Thoughts on the Future of Finance. Available at https://gendal.me/2016/11/08/ondistributed-databases-and-distributed-ledgers/ (26/01/2020)

Buterin, V. (2017) "The Meaning of Decentralization." Medium. Available at https://medium.com/@VitalikButerin/the-meaning-of-decentralizationaocg2b76a274\#.ttg7tzspw (25/01/2020)

Cai, C. W. (2019) "Triple-entry Accounting with Blockchain: How Far Have We Come?" Accounting \& Finance. Accounting and Finance Association of Australia and New Zealand.

Carlyle, J. (2020) "How "Public-permissioned" Blockchains are not an Oxymoron." R3. Available at https://www.r3.com/blog/how-public-permissioned-blockchains-are-not-an-oxymoron/ $(27 / 02 / 2020)$

Chandler, A. D. (1977). "The Visible Hand: Managerial Revolution in American Business." Harvard, United States of America: Harvard University Press.

Edwards, J. D. (1960) "Early Bookkeeping and its Development into Accounting." Business History Review, 34 (04), 446-458.

Faccia, A., Moşteanu, N. R., and Leonardo, L. P. (2020) "Blockchain Hash, the Missing Axis of the Accounts to Settle the Triple Entry Bookkeeping System." ICIME 2020: Proceedings of the 
2020 12th International Conference on Information Management and Engineering, September 2020, 18-23.

Garay, J.; Kiayias, A. (2020) "Sok: A Consensus Taxonomy in the Blockchain Era." In Cryptographers' Track at the RSA Conference, 284-318.

Ge, J. 2005. "Accounting English." Available at http://abook.cn/pdf/H-0535.0101.pdf

Ginigoada Foundation (2017) "Introduction to Bookkeeping: A Flexible Learning Course." Available at http://oasis.col.org/bitstream/handle/11599/2749/2017_Ginigoada-

BisnisFoundation_Introduction-to-Bookkeeping_.pdf

Glaser, F.; Bezzenberger, L. (2015). „Beyond Cryptocurrencies-a Taxonomy of Decentralized Consensus Systems." In 23rd European Conference on Information Systems (ECIS), Münster, Germany.

Grange, E. (2016) "Mesh World P2P Simulation Hypothesis." DelphiTools. Available at https://www.delphitools.info/DWSH/ (25/01/2020)

Grigg, I. (2005b) "Triple Entry Accounting." Systemics Inc. Available at https://iang.org/papers/triple_entry.html

Grigg, I. 2011. "Is BitCoin a Triple Entry System?" Financial Cryptography. Available at https://financialcryptography.com/mt/archives/001325.html

Grigg, I. (2016) "Yup - Todd Boyle's concept could not work without a server, a quorum or a blockchain. That's why it's called triple entry." Twitter Post. Available at https://twitter.com/iang_fc/status/775234399847710720 (26/01/2020)

Grigg, I. (2017a) "EOS: An Introduction." EOS Whitepaper. Available at https://whitepaperdatabase.com/eos-whitepaper (10/01/2020)

Grigg, I. (2017b) "Oddly, Yuji called it 3E bookkeeping, we called it 3E accounting, and arguably we should have reversed." Twitter Post. Available at https://twitter.com/iang_fc/status/880691386735112192 (25/01/2020)

Grigg, I. (2019) "It's tricky - term was coined 20 years ago by Todd Boyle. My paper was 2004 or so. Oddly - paper is "3E accounting" but techniques are really bookkeeping. Yuri ljiri's work was originally labelled "triple entry bookkeeping" but is really accounting... Confusion 
abounds..."

Twitter

Post.

Available

at

https://twitter.com/iang_fc/status/1182660123245928449(25/01/2020)

Gröblacher, M.; Mizdraković, V. (2019) "Triple-entry Bookkeeping: History and Benefits of the Concept." Digitization and Smart Financial Reporting, 58-61.

Haugen, R.; McCarthy, W. E. (2000) "REA, a semantic model for Internet supply chain collaboration." OOPSLA Workshop on Business Object Components: Enterprise Application Integration, OOPSLA.

Hildebrand, G. (2018) "The Strikingly Simple New Way To Get Paid in Cryptocurrency." Medium. Available at https://medium.com/gilded/the-strikingly-simple-new-way-to-get-paid-incryptocurrency-6ogecbd8a80a (30/01/2020)

Holman, G. K. (2019) "Blockchain and eBusiness." LinkedIn. Available at https://www.linkedin.com/pulse/blockchain-ebusiness-ken-holman/ (11/02/2020)

Ibañez, J. I.; Bayer, C. N.; Tasca, P.; Xu, J. (2020) "REA, Triple-entry Accounting and Blockchain: Converging Paths to Shared Ledger Systems." Social Science Research Network (SSRN). Available at http://dx.doi.org/10.2139/ssrn.3602207

ICAEW (2018) "Blockchain and the Future of Accountancy." Institute of Chartered Accountants in England and Wales. Available at https://www.icaew.com/technical/technology/blockchain/blockchain-articles/blockchainandthe-accounting-perspective

Ijiri, Y. (1982) "Triple-entry Bookkeeping and Income Momentum." American Accounting Association: Sarasota.

Ismail, L.; Hameed, H.; AlShamsi, M.; AlHammadi, M.; AlDhanhani, N. (2019) "Towards a Blockchain Deployment at UAE University: Performance Evaluation and Blockchain Taxonomy." In Proceedings of the 2019 International Conference on Blockchain Technology, 30-38.

Labazova, O.; Dehling, T.; Sunyaev, A. (2019). "From Hype to Reality: A Taxonomy of Blockchain Applications." In Proceedings of the 52nd Hawaii International Conference on System Sciences (HICSS 2019), 4555-4564. 
Mehmood, F.; Cheah, I.; Golash, R.; Ma, L. (2019) "Ledgerium Whitepaper, Version 2.2." Ledgerium. Available at https://whitepaper.ledgerium.io (28/01/2019)

McCarthy, W. E.; Holman, G. K. (2019) "Blockchain and eBusiness. The Open-edi Distributed Business Transaction Repository. ISO/IEC 15944-21 OeDBTR." E-Invoicing Exchange Summit Singapore 2019.

Michael, S. (2019) "Plain Text Accounting." Plain Text Accounting. Available at https://plaintextaccounting.org (10/01/2020)

Mohsin, A. H.; Zaidan, A. A.; Zaidan, B. B.; Albahri, O. S.; Albahri, A. S.; Alsalem, M. A.; Mohammed, K. I. (2019) "Blockchain Authentication of Network Applications: Taxonomy, Classification, Capabilities, Open Challenges, Motivations, Recommendations and Future Directions." Computer Standards \& Interfaces, 64, 41-60.

Odom, C. (2015) "Open-Transactions: Secure Contracts Between Untrusted Parties." OpenTransactions White Paper. Available at http://www.opentransactions.org/opentransactions.pdf (19/12/2019)

Pacio (2019b) "Pacio White Paper." Pacio. Available at https://pacio.io/docs/PacioWhitePaper.pdf $(06 / 01 / 2020)$

Pacio (2020) "Pacio White Paper." Pacio. Available at https://pacio.io/docs/PacioWhitePaper.pdf $(07 / 02 / 2020)$

Peters-Richardson, J. (2011) Introduction to Accounting. Ministry of Education, Trinidad and Tobago Commonwealth of Learning. Available at http://oasis.col.org/bitstream/handle/11599/2463/2011_VUSSC Intro-Accounting.pdf

Pompliano, A. (2019) "Funding The Future of Finance." Off The Chain. Available at https://offthechain.substack.com/p/funding-the-future-of-finance (19/02/2020)

Request (2018) "The Future of Commerce: A Decentralized Network for Payment Requests." Request Whitepaper. Available at https://request.network/assets/pdf/request_whitepaper.pdf (20/07/2020) 
Rukhiran, M., and Netinant, P. (2018) "The House Bookkeeping Conceptual Framework for Supporting Adaptability Using Three Dimensions Layering." Advanced Science Letters, 24 (7), 5234-5238.

Sarkintudu, S. M.; Ibrahim, H. H.; Abdwahab, A. B. (2018)." Taxonomy Development of Blockchain Platforms: Information Systems Perspectives." In AIP Conference Proceedings, 2016, 1, 020130-1-020130-7.

Schollmeier, R. (2001) "A Definition of Peer-to-peer Networking for the Classification of Peer-topeer Architectures and Applications." Proceedings of the First International Conference on Peer-to-Peer Computing, 101-102. IEEE.

Tanenbaum, A. S.; Van Steen, M. (2016) "A Brief Introduction to Distributed Systems." Computing, 98(10), 967-1009.

Tasca P.; Tessone C. (2019) "Taxonomy of Blockchain Technologies. Principles of Identification and Classification." Ledger, 4.

Tholen, J.; Vries, D. d.; Daluz, A.; Antonovici, C. C., Brug, W. v.; Abelson, R.; Lovell, D. (2019) "Is There a Role for Blockchain in Responsible Supply Chains?" Joint document by the OECD and KPMG. OECD Global Blockchain Policy Forum.

Tyra, J. M. (2014) "Triple Entry Bookkeeping With Bitcoin." Bitcoin Magazine. Available at https://bitcoinmagazine.com/articles/triple-entry-bookkeeping-bitcoin-1392069656

Victorovna, N. V. (2015) "F. V. Ezersky and the Development of Accounting Thought and Practices in Russia." Vestnik NSUEM, 4, 160-170.

Vollmer, H. (2003) "Bookkeeping, Accounting, Calculative Practice: the Sociological Suspense of Calculation." Critical Perspectives on Accounting, 14 (3), 353-381

Walsh, C.; O'Reilly, P.; Gleasure, R.; Feller, J.; Li, S.; Cristoforo, J. (2016). "New Kid on the Block: A Strategic Archetypes Approach to Understanding the Blockchain." In ICIS 2016 Proceedings, 6.

Wild, J. J., Shaw, K. W., and Chiappetta, B. (2011) "Fundamental Accounting Principles." New York, United States of America: McGraw-Hill/Irwin. 
Xu, X.; Weber, I.; Staples, M.; Zhu, L.; Bosch, J.; Bass, L.; Pautasso, C.; Rimba, P. (2017). "A Taxonomy of Blockchain-based Systems for Architecture Design." In 2017 IEEE International Conference on Software Architecture (ICSA), 243-252.

\section{APPENDIX A: ACRONYMS}

\begin{tabular}{|l|l|}
\hline B2B & Business-to-business \\
\hline CDEA & Classic double-entry accounting \\
\hline DBT & Distributed Book Technology \\
\hline DJT & Distributed Journal Technology \\
\hline DLT & Distributed Ledger Technology \\
\hline G2G & Government to Government \\
\hline IEC & International Electrotechnical Commission \\
\hline ISO & International Organization for Standardization \\
\hline OeDBTR & Open-edi Distributed Business Transaction Repository \\
\hline PTR & Public Transaction Repository \\
\hline REA & Resources, Events, Agents \\
\hline STR & Shared Transaction Repository \\
\hline TEA & Triple-entry accounting \\
\hline TEB & Triple-entry bookkeeping \\
\hline
\end{tabular}

\section{APPENDIX B: ACKNOWLEDGEMENTS}

We thank the following individuals for answering our questions per email correspondence or per interview: 


\begin{tabular}{|l|l|}
\hline \multicolumn{1}{|c|}{ Individual } & \multicolumn{1}{c|}{ Position } \\
\hline Chris Odom & Founder of Open-Transactions \\
\hline David Hartley & CEO of Pacio \\
\hline G. Ken Holman & $\begin{array}{l}\text { CTO at Crane Softwrights Ltd and former } \\
\text { editor of ISO/IEC 15944-21 }\end{array}$ \\
\hline Ian Grigg & Co-founder at Solidus/Chamapesa \\
\hline Jason Meyers & Founder at Auditchain \\
\hline Robert Haugen & Developer at Mikorizal Software \\
\hline Todd Boyle & Founder at International Accounting Services \\
\hline
\end{tabular}

